\title{
An exploration of sociological factors that may contribute to physician burnout
}

Jennifer Gray

\begin{abstract}
A discussion about mental health and how it relates to the medical profession is incomplete without exploring the concept of burnout. The implications of physician burnout are profound, and it is plaguing the medical community at epidemic rates. Current research focuses on which occupational factors may be contributing to this problem. Other approaches involve investigating the efficacy of building resilience at the individual level as a means of combatting burnout. Examining this issue through a broader lens and considering sociocultural factors that may be influencing how medicine is experienced by those in the field is remarkably untouched in the literature. This article will discuss how several changes in contemporary Canadian society may be underlying factors in physician burnout. The increasing penetrance of the internet into patient-physician interactions, the rise of online review platforms, and widespread secularization of society will be addressed in this article. This is a preliminary discussion to fortify current initiatives aimed at promoting awareness and the prevention of physician burnout.
\end{abstract}

\section{INTRODUCTION}

Among the issues experienced by physicians, burnout is perhaps the most problematic and pervasive. Though there is a growing body of research dedicated to understanding its inciting and mitigating factors, a majority of the literature has focused on its prevalence rather than striving to identify the root cause. ${ }^{1}$ The role that societal factors play in this epidemic remains unclear. ${ }^{2}$ In a field submerged within a sea of culture, politics, and history, it is vital to adopt a sociological lens in an effort to fully deconstruct, and subsequently prevent, burnout. In this article we will discuss several salient elements of change in Canadian contemporary society and how they may relate to physician burnout.

Physician burnout is defined as a work-related syndrome consisting of emotional exhaustion, depersonalization, and a reduced sense of personal accomplishment. ${ }^{3}$ An online survey conducted by the Canadian Medical Association in 2018 reported that $30 \%$ of medical professionals are affected by burnout, with significantly higher rates in residents. ${ }^{4}$ It has been associated with addiction, depression, and suicide in medical professionals, as well as adverse effects on patient care, public safety, workforce retention, and subsequently, elevated financial burdens on the health care and education systems. ${ }^{2,5-15}$ A study conducted in the United States by Shanafelt et al found that in 2014, 54.4\% of surveyed physicians reported at least one marker of burnout, a statistically significant increase from the $45.5 \%$ measurement just three years prior in
2011. ${ }^{16}$ What is causing this trend? It is difficult to determine with certainty, but increased awareness alone cannot account for the recent rise.

Many have proposed that a profound increase in clerical and computer duties at the expense of direct patient care may be contributing to professional dissatisfaction and burnout. ${ }^{17-19}$ Other areas of literature focus on personality traits, coping strategies, and the level of resilience in the individual. ${ }^{20-22}$ This places the onus of combatting burnout on already strained individuals. Building resilience is important, but dismantling some of the underlying contributors that create the adversity of burnout itself must not be overlooked. Medical schools across the country are striving to instill a preventative "wellness" discourse into the perspectives of their students. Hospitals, clinics, and other workplaces are beginning to adopt the organizational and occupational strategies to alleviate burnout at the systemic level. What remains to be investigated is how our world is changing the experience and practice of medicine for those in the field. Without it, the picture is simply incomplete, and the plague will persist.

\section{A CONSULT WITH DR. GOOGLE}

As Internet-enabled devices have become ubiquitous, the Internet has shifted into the epicentre of almost every interaction with our world. It is nearly impossible for the average Canadian to function in their day-to-day lives without using the Internet for their work, leisure, or social activities. With a wealth of information and opinions available at our fingertips, perhaps it comes as no surprise that many may consult "Doctor Google" or WebMD for their health concerns. Though freely accessible knowledge can often be empowering, patients may not have the necessary understanding and education to prudently interpret and apply this vast knowledge base that they can now access. This may yield erroneous beliefs that can permeate a patient-physician relationship and lead to problematic power dynamics. ${ }^{23}$ For example, a patient may begin a medical consultation with a preformed directive based on Internet diagnoses, and insist on contraindicated investigations or interventions. Unattached to any specific provider and unbound by hospital or medical organization policies, patients can demand whatever they feel is required until someone concedes. This type of behaviour not only undermines the extensive education and training that medical professionals undergo to properly manage patient conditions and minimize unnecessary treatment, it also places additional stress and frustration on physicians who are already implored to be mindful of their use of precious health care resources. 


\section{TRIAL BY SOCIAL MEDIA}

The demands of physicians are further compounded by online review platforms. RateMDs.com is a popular American website founded in 2004 that allows people to post anonymously-written comments online about their physicians, and features a large proportion of Canadian physicians. ${ }^{24}$ Both the Canadian Medical Association and the Canadian Medical Protective Association have contacted the site administrators over the years to address alleged defamatory and libellous remarks. ${ }^{24}$ When public safety and wellbeing are at stake, the ethical conduct and clinical performance of physicians should be held to the highest standard. There should be appropriate consequences when these standards are not met. However, the opportunity to file legitimate concerns with appropriate regulating bodies has always existed. Is it fair to physicians to allow the public to log on to an anonymous review website and post whatever fleeting impression they may have of their care providers? Regardless of one's opinion on this matter, it can be unsettling for physicians to read these sometimes unverifiable and potentially defamatory or libellous claims, or to envision the possibility of future patients, learners, or colleagues viewing them.

\section{A SECULARIZING SOCIETY}

In addition to difficult personalities and the perils of technology, a career in medicine necessitates regularly grappling with some of the toughest aspects of the human experience: pain, suffering, and death. In contrast to our previous discussion, this aspect of the field is static. Medicine, by virtue of its focus on disease, always has and always will require its practitioners to face morbidity and mortality. Until recently, human civilization would turn to religion for answers to their questions about life, meaning, and death. Western society has experienced widespread secularization, despite the persistence of these unknowns. Inverse correlations have been noted between measures of spirituality and psychological distress among both medical students and physicians. ${ }^{11,25}$ These findings suggest that religion may offer an effective framework for medical professionals to make sense of stressful events that they face and subsequently, prevent burnout. Unfortunately, but perhaps not surprisingly, physicians are cited to be a remarkably secular population, which degrades the viability of this potentially protective factor in this group. ${ }^{11}$ An additional consequence of societal secularization is that the guidance patients may have previously sought from their religious leaders is often sought directly from physicians. With issues and questions that stretch far beyond the realm of medicine and even humanity, this burden is unimaginable for any professional.

\section{DISCUSSION AND CONCLUDING REMARKS}

Though the devastating effects of physician burnout are increasingly being recognized, an understanding of its root causes remains unaddressed. Recently, mitigating factors of burnout have been identified, and initiatives to address these factors are being implemented in the occupational environment. Additionally, strategies to promote resilience at the individual level are the focus of many medical schools and organizations in Canada. Despite these interventions, the problem persists. As noted previously, a sociological approach to this issue is largely unexplored. Select societal changes are proposed in this article as potential contributing factors in this epidemic. The unregulated accessibility of medical information online may be placing strain on the patient-physician relationship. The rise of online review platforms presents a constant possibility of uninhibited, anonymous public scrutiny of physicians, prohibiting bad days or mistakes. The widespread secularization of society has not only eroded the potential protection that a belief system can have for alleviating burnout, it has redistributed the burden of navigating through the most difficult waters of the human experience onto medical professionals. In conclusion, this brief discussion elucidates how changes in our world are impacting the ways in which medicine is experienced and practiced by modern physicians. Acknowledging these influences may direct future research and better inform initiatives aimed at preventing physician burnout.

\section{REFERENCES}

1. Squiers JJ, Lobdell KW, Fann JI, et al. Physician burnout: are we treating the symptoms instead of the disease? Ann Thorac Surg. 2017 Oct;104(4):1117-22. https://doi.org/10.1016/j.athoracsur.2017.08.009

2. West CP, Dyrbye LN, Shanafelt TD. Physician burnout: contributors, consequences and solutions. J Intern Med. 2018 Jun;283(6):516-29. https://doi.org/10.1111/joim.12752

3. Maslach C, Jackson S, Leiter M. Maslach burnout inventory manual. 3rd ed. Palo Alto (CA): Consulting Psychologists Press; 1996.

4. CMA national physician health survey: a national snapshot [Internet]. Ottawa (ON): Canadian Medical Association; 2018 Oct [cited 2019 Mar 19]. Available from: https://www.cma.ca/sites/default/files/2018-11/ nph-survey-e.pdf.

5. Gallery ME, Whitley TW, Klonis LK, et al. A study of occupational stress and depression among emergency physicians. Ann Emerg Med. 1992 Jan;21(1):58-64. https://doi.org/10.1016/S0196-0644(05)82238-3

6. Erdur B, Ergin A, Turkcuer I, et al. A study of depression and anxiety among doctors working in emergency units in Denizli, Turkey. Emerg Med J. 2006 Oct;23(10):759-63. https://doi.org/10.1136/ emj.2006.035071

7. Burbeck R, Coomber S, Robinson SM, et al. Occupational stress in consultants in accident and emergency medicine: a national survey of levels of stress at work. Emerg Med J. 2002 May;19:234-8. https://doi. org/10.1136/emj.19.3.234

8. Lloyd S, Streiner DL, Shannon S. Burnout, depression, life and job satisfaction among Canadian emergency physicians. J Emerg Med. 1994 Jul;12(4):559-65. https://doi.org/10.1016/0736-4679(94)90360-3

9. Oreskovich MR, Shanafelt T, Dyrbye LN, et al. The prevalence of substance use disorders in American physicians. Am J Addict. 2015 Jan;24(1):30-8. https://doi.org/10.1111/ajad.12173

10. West CP, Huschka MM, Novotny PJ, et al. Association of perceived medical errors with resident distress and empathy: a prospective longitudinal study. JAMA. 2006 Sep;296(9):1071-8. https://doi. org/10.1001/jama.296.9.1071

11. Salmoirago-Blotcher E, Fitchett G, Leung K, et al. An exploration of the role of religion/spirituality in the promotion of physicians' wellbeing in emergency medicine. Prev Med Rep. 2016 Feb;3:189-95. https://doi.org/10.1016/j.pmedr.2016.01.009

12. Dyrbye LN, Massie FS Jr, Eacker A, et al. Relationship between 


\section{FEATURE ARTICLE}

burnout and professional conduct and attitudes among US medical students. JAMA. 2010 Sep;304(11):1173-80. https://doi.org/10.1001/ jama.2010.1318

13. Shanafelt TD, Balch CM, Beschamps G, et al. Burnout and medical errors among American surgeons. Ann Surg. 2010 Jun;251(6):9951000. https://doi.org/10.1097/SLA.0b013e3181bfdab3

14. Shanafelt TD, Bradley KA, Wipf JE, et al. Burnout and self-reported patient care in an internal medicine residency program. Ann Intern Med. 2002 Mar;136(5):358-67. https://doi.org/10.7326/0003-4819-1365-200203050-00008

15. Firth-Cozens J, Greenhalgh J. Doctors' perceptions of the links between stress and lowered clinical care. Soc Sci Med. 1997 Apr;44(7):1017-22. https://doi.org/10.1016/S0277-9536(96)00227-4

16. Shanafelt TD, Hasan O, Dyrhye LN, et al. Changes in burnout and satisfaction with work-life balance in physicians and the general US working population between 2011 and 2014. Mayo Clin Proc. 2015 Dec;90(12):1600-13. https://doi.org/10.1016/j.mayocp.2015.08.023

17. Block L, Habicht R, Wu AW, et al. In the wake of the 2003 and 2011 duty regulations, how do internal medicine interns spend their time? J Gen Intern Med. 2013 Aug;28(8):1042-7. https://doi.org/10.1007/ s11606-013-2376-6

18. Chung RS, Ahmed N. How surgical residents spend their training time: the effect of a goal-oriented work style on efficiency and work satisfaction. Arch Surg. 2007 Mar;142(3):249-52. https://doi. org/10.1001/archsurg.142.3.249

19. Downing NL, Bates DW, Longhurst CA. Physician burnout in the electronic health record era: are we ignoring the real cause? Ann Intern Med. 2018 Jul;169(1):50-1. https://doi.org/10.7326/M18-0139

20. Zwack J, Schweitzer J. If every fifth physician is affected by burnout, what about the other four? Resilience strategies of experienced physicians. Acad Med. 2013 Mar;88(3):382-9. https://doi.org/10.1097/ ACM.0b013e318281696b

21. Balch CM, Shanafelt T. Combating stress and burnout in surgical practice: a review. Adv Surg. 2010 Sept;44:29-47. https://doi. org/10.1016/j.yasu.2010.05.018

22. Campbell DA Jr, Sonnad SS, Eckhauser FE, et al. Burnout among American surgeons. Surgery. 2001 Oct;130(4):696-705. https://doi. org/10.1067/msy.2001.116676

23. Kilbride MK, Joffe S. The new age of patient autonomy: Implications for the patient-physician relationship. JAMA. 2018 Nov;320(19):19734. https://doi.org/10.1001/jama.2018.14382

24. Mackay B. RateMDs.com nets ire of Canadian physicians. CMAJ. 2007 Mar;176(6):754. https://doi.org/10.1503/cmaj.070239

25. Wachholtz A, Rogoff M. The relationship between spirituality and burnout among medical students. J Contemp Med Educ. 2013;1(2):8391. https://doi.org/10.5455/jcme.20130v104060612 